\title{
Expression of MUC1, MUC2, MUC5AC and MUC6 in cholangiocarcinoma: Prognostic impact
}

\author{
SIN YOUNG PARK ${ }^{1}$, SANG JAE ROH ${ }^{1}$, YO NA KIM ${ }^{1}$, SUNG ZOO KIM ${ }^{2}$, HO SUNG PARK ${ }^{1}$, KYU YUN JANG $^{1}$, \\ MYOUNG JA CHUNG ${ }^{1}$, MYOUNG JAE KANG ${ }^{1}$, DONG GEUN LEE ${ }^{1}$ and WOO SUNG MOON ${ }^{1}$ \\ Departments of ${ }^{1}$ Pathology and ${ }^{2}$ Physiology, Chonbuk National University, Medical School, \\ Institute for Medical Sciences, Research Institute of Clinical Medicine and The Center \\ for Healthcare Technology Development, Jeonju, Chonbuk 561-756, Korea
}

Received March 13, 2009; Accepted June 3, 2009

\section{DOI: $10.3892 /$ or_00000485}

\begin{abstract}
Mucin is a high molecular weight glycoprotein that plays an important role to protect the gastrointestinal tract epithelium. However, in cancer cells and during cancer progression, the expression profile of mucins is altered and expression of some mucins is correlated with prognosis for certain malignancies. The aim of this study was to determine the relationship between the expression of MUC1, MUC2, MUC5AC and MUC6 in cholangiocarcinoma and clinicopathological parameters as well as patient survival. In addition, this study was performed to identify whether immunohistochemical staining for mucins is useful to differentiate cholangiocarcinoma from adenocarcinoma of the pancreas and gallbladder. Immunohistochemical staining for MUC1, MUC2, MUC5AC and MUC6 was performed for 85 cases of cholangiocarcinoma, including 34 cases of intrahepatic cholangiocarcinoma (ICC), 51 cases of extrahepatic cholangiocarcinoma (ECC), 11 cases of gallbladder adenocarcinoma and 14 cases of pancreas adenocarcinoma. For cholangiocarcinomas, positivity of immunohistochemical staining for MUC1, MUC2, MUC5AC and MUC6 was 65.8, $23.5,61.1$ and $14.1 \%$, respectively. For cholangiocarcinomas, MUC1 positivity was determined to be statistically significant for poor differentiation $(\mathrm{p}=0.002)$, $\mathrm{T}$ category $(\mathrm{p}=0.003)$, gross type (ICC, $\mathrm{p}=0.005 ; \mathrm{ECC}, \mathrm{p}=0.006)$ and poor patient survival ( $\mathrm{p}=0.015)$. MUC5AC was more frequently expressed in advanced tumors $(\mathrm{p}=0.013)$. MUC6 expression was significantly detected in well-differentiated cholangiocarcinomas $(p=0.006)$. There was no significant difference for the mucin staining patterns of cholangiocarcinomas, pancreatic adenocarcinomas and gallbladder adenocarcinomas. These results
\end{abstract}

Correspondence to: Dr Woo Sung Moon, Department of Pathology, Chonbuk National University, Medical School, Institute for Medical Sciences, Research Institute of Clinical Medicine and The Center for Healthcare Technology Development, Jeonju, Chonbuk 561-756, Korea

E-mail: mws@chonbuk.ac.kr

Key words: mucin, cholangiocarcinoma, immunohistochemistry indicate that MUC1 expression in cholangiocarcinomas is closely related to dedifferentiation, infiltrative growth pattern and patient survival. Our results suggest that the expression of MUC1 might be associated with the progression of cholangiocarcinoma.

\section{Introduction}

Cholangiocarcinoma (CC) accounts for about 3\% of all gastrointestinal cancers with a 5-year survival of $20-30 \%$ after surgery $(1,2)$. A CC arises from the ductal epithelium of the biliary tree. Depending on location, a CC can be classified as an intrahepatic cholangiocaricnoma (ICC) and an extrahepatic cholangiocarcinoma (ECC). Due to a poor prognosis, investigation of prognostic factors is very valuable for the treatment of patients with a CC.

Mucins are high molecular weight glycoproteins that are heavily glycosylated with many oligosaccharide side chains linked to a protein backbone called apomucin. During the past several years, a number of human mucins (MUC1-MUC20) have been identified $(3,4)$. Mucins can be broadly subdivided into two groups: proteins that are secreted and form extracellular gels (MUC2, MUC5AC, MUC5B and MUC6) and membrane bound mucins (MUC1, MUC3 and MUC4). Mucins are present at the surface of most epithelial cells and play a role in protection and lubrication. It has been suggested that expression of mucins is associated with clinicopathological findings and patient survival in tumors that arise in various organs (5-8). MUC1 overexpression is most evident, and these rigid mucin glycoproteins located on cancer cells play a role in metastasis by inhibiting tumor cell adhesion and allowing escape from immune surveillance (9-11). Therefore, altered expression of mucins appears to be involved in tumor biology. Despite several studies, the role of expression of mucins in $\mathrm{CC}$ is still controversial and no definite conclusions have been reached.

Identification of the tissue of origin for tumors that arise in and around the biliary tract is particularly difficult, especially in advanced tumor stages, as the regions are contiguous. Moreover, the cytological differentiation of a $\mathrm{CC}$ and a pancreatic or gallbladder adenocarcinoma can be difficult. Nevertheless, a correct diagnosis is essential to select the proper therapy and to determine patient prognosis. 

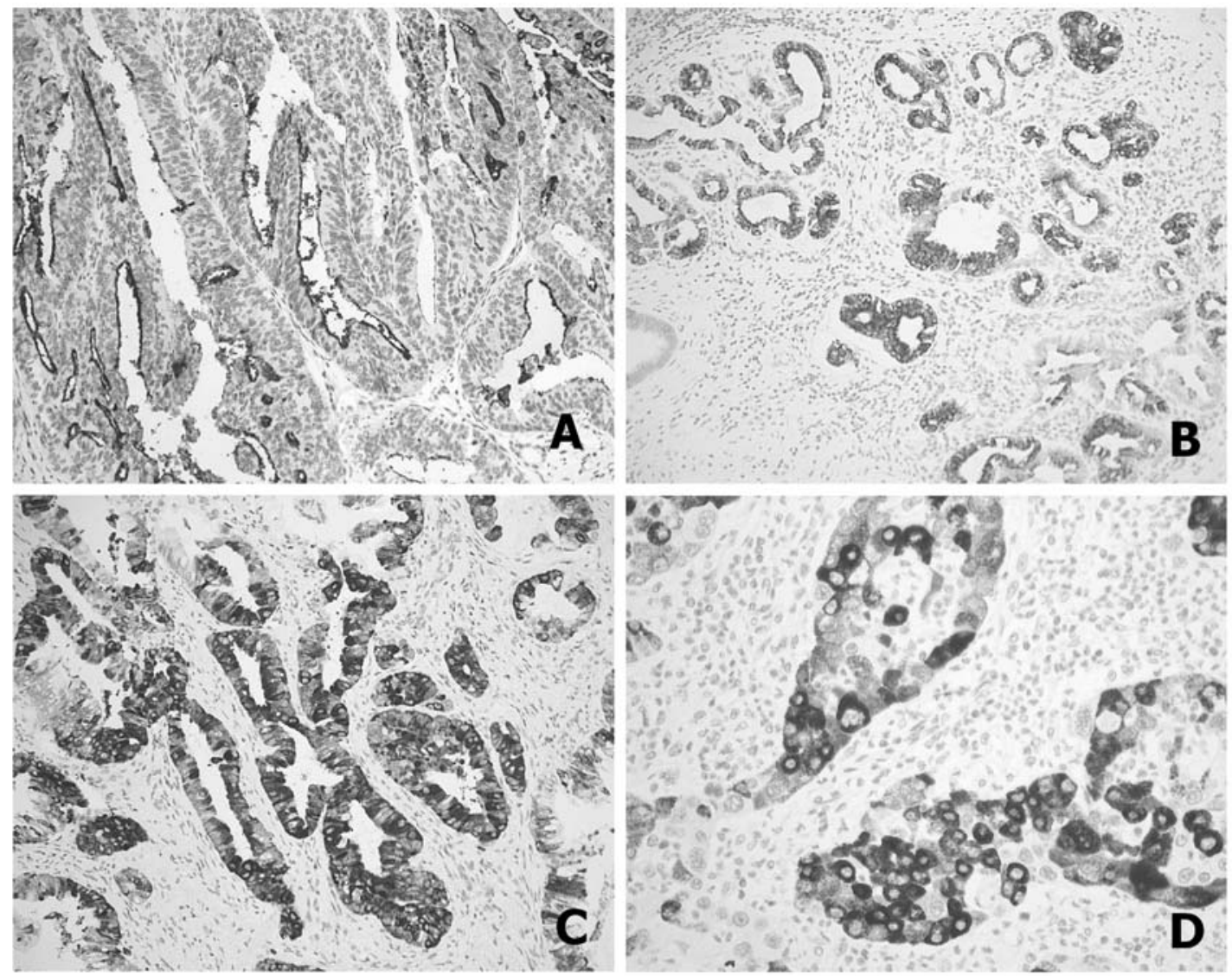

Figure 1. Representative immunohistochemical staining is shown. (A) MUC1 expression in a cholangiocarcinoma is shown. (B) MUC6 expression in a cholangiocarcinoma is shown. (C) MUC5AC expression in a cholangiocarcinoma is shown. (D) MUC5AC expression in a gallbladder adenocarcinoma is shown.

In the current study, we have analyzed the association of MUC1, MUC2, MUC5AC and MUC6 expression with the clinical and pathological findings and with survival in patients with CC. In addition, we have evaluated whether differential patterns of expression of mucins can be used to distinguish $\mathrm{CC}$ from gallbladder and pancreatic adenocarcinoma.

\section{Materials and methods}

Tissue specimens. A total of $85 \mathrm{CC}$ (34 cases of ICC and 51 cases of ECC), 14 pancreatic adenocarcinoma and 11 gallbladder adenocarcinoma samples were obtained from patients who had undergone surgery between 1998 and 2007 at Chonbuk National University Hospital. Of the 85 patients with CC, 58 patients were male and 27 patients were female. The mean age of the patients at the time of surgery was 63.8 years (age range, 44-82 years). Seven patients had hepatolithiasis and five patients had clonorchiasis. Patients were chosen for analysis based on the availability of paraffinembedded tissue. Hematoxylin and eosin stained slides were reviewed and were graded according to the WHO classification (12). The following histological features were also examined: vessel invasion, nerve invasion and the presence of a lymph node metastasis at the time of surgery. The pathological stage was reclassified according to the American Joint Committee on Cancer Staging (AJCC) 6th edition (13). Based on gross appearance, ICCs were classified as mass-
Table I. Difference in the expression of mucins for cholangiocarcinoma, gallbladder adenocarcinoma and pancreatic adenocarcinoma.

\begin{tabular}{|c|c|c|c|c|}
\hline \multirow[b]{2}{*}{ Tumor type } & \multicolumn{4}{|c|}{ Mucin expression (\%) } \\
\hline & MUC1 & MUC2 & MUC5AC & MUC6 \\
\hline \multicolumn{5}{|l|}{$\begin{array}{l}\text { Cholangio- } \\
\text { carcinoma }\end{array}$} \\
\hline \multicolumn{5}{|l|}{ Total, 85} \\
\hline Positive & $56(65.8)$ & $20(23.5)$ & $52(61.1)$ & $12(14.1)$ \\
\hline Negative & $29(34.2)$ & $65(76.5)$ & $33(38.9)$ & $73(85.9)$ \\
\hline \multicolumn{5}{|c|}{$\begin{array}{l}\text { Gallbladder } \\
\text { adenocarcinoma }\end{array}$} \\
\hline \multicolumn{5}{|l|}{ Total, 11} \\
\hline Positive & $10(90.9)$ & $3(27.3)$ & $9(81.8)$ & $4(36.4)$ \\
\hline Negative & $1 \quad(9.1)$ & $8(72.7)$ & $2(18.2)$ & $7(63.6)$ \\
\hline \multicolumn{5}{|c|}{$\begin{array}{l}\text { Pancreatic } \\
\text { adenocarcinoma }\end{array}$} \\
\hline Positive & $11(78.6)$ & $1 \quad(7.1)$ & $11(78.6)$ & $4(28.6)$ \\
\hline Negative & $3(21.4)$ & $13(92.9)$ & $3(21.4)$ & $10(71.4)$ \\
\hline
\end{tabular}


Table II. Difference in the phenotype expression of mucins for intrahepatic and extrahepatic cholangiocarcinoma.

\begin{tabular}{lccc}
\hline & \multicolumn{2}{c}{ Mucin expression } & \\
\cline { 2 - 4 } & ICC (\%) & ECC (\%) & P-value \\
\hline MUC1 & & & \\
Positive & $19(55.8)$ & $37(72.5)$ & 0.209 \\
Negative & $15(44.2)$ & $14(27.5)$ & \\
MUC2 & & & \\
Positive & $10(29.4)$ & $10(19.6)$ & 0.314 \\
Negative & $24(70.6)$ & $41(80.4)$ & \\
MUC5AC & & & \\
Positive & $16(47.1)$ & $36(70.6)$ & \\
Negative & $18(52.9)$ & $15(29.4)$ & \\
MUC6 & & & \\
Positive & $5(14.7)$ & $7(13.7)$ & \\
Negative & $29(85.3)$ & $44(86.3)$ & \\
\hline ICC, intrahepatic cholangiocarcinoma; ECC, extrahepatic cholan- \\
giocarcinoma.
\end{tabular}

forming, periductal-infiltrative and intraductal growth types. ECCs were classified as periductal-infiltrative and intraductal growth types. Clinical data, including age, sex, presence of a distant metastasis and patient overall survival were obtained from the medical records. This study received local ethics committee approval from the institutional reviewed board of Chonbuk National University Hospital.

Immunohistochemistry. Immunohistochemical analysis was performed by the streptavidin-biotin-peroxidase (SAB) method. Paraffin blocks with representative areas of the tumors were cut into 4- $\mu \mathrm{m}$ thick tissue sections, and endogenous activity was quenched by incubation with $3 \%$ hydrogen peroxidase for $30 \mathrm{~min}$ after deparaffinization and hydration. Antigen retrieval was subsequently carried out. The primary antibodies used in this investigation were MUC1 (Clone Ma695, Novocastra, Leica Microsystems, Wetzlar, Germany), MUC2 (Clone Ccp58, Novocastra), MUC5AC (Clone CLH2, Novocastra) and MUC6 (CLH5, Novocastra); these antibodies were used at 1:100 dilution. Diaminobenzidine was used as a chromogen and the tissues were counterstained with hematoxylin. Two pathologists (W.S.M. and S.Y.P.) with no previous knowledge of the clinicopathological details evaluated all of the tissue slides. Distinct staining in $>10 \%$ of the tumor cells was recorded as positive.

Table III. Correlation between the expression of mucins and clinicopathological factors for cholangiocarcinoma.

\begin{tabular}{|c|c|c|c|c|c|c|c|c|c|}
\hline \multirow[b]{2}{*}{ Category } & \multirow[b]{2}{*}{ Total } & \multicolumn{2}{|c|}{ MUC1 } & \multicolumn{2}{|c|}{ MUC2 } & \multicolumn{2}{|c|}{ MUC5AC } & \multicolumn{2}{|c|}{ MUC6 } \\
\hline & & $+(\%)$ & P-value & $+(\%)$ & P-value & $+(\%)$ & P-value & $+(\%)$ & $\mathrm{P}$-value \\
\hline Differentiation & & & 0.002 & & 0.234 & & 0.174 & & 0.010 \\
\hline Well & 37 & $16(43)$ & & $12(32)$ & & $23(62)$ & & $10(27)$ & \\
\hline Moderately & 37 & $31(84)$ & & $6(16)$ & & $25(68)$ & & $2(5)$ & \\
\hline Poorly & 11 & $9(91)$ & & $2(18)$ & & $4(36)$ & & $0 \quad(0)$ & \\
\hline T category & & & 0.003 & & 0.057 & & 0.013 & & 0.465 \\
\hline $\mathrm{T} 1$ & 40 & $20(50)$ & & $13(33)$ & & $21(53)$ & & $4(10)$ & \\
\hline$\geq \mathrm{T} 2$ & 45 & $36(80)$ & & 7 (16) & & $33(73)$ & & $8(18)$ & \\
\hline LN metastasis & & & 0.586 & & 0.578 & & 0.400 & & 0.221 \\
\hline Positive & 18 & $12(67)$ & & $4(22)$ & & $12(67)$ & & $1(6)$ & \\
\hline Negative & 67 & $44(66)$ & & $16(24)$ & & $40(60)$ & & $11(16)$ & \\
\hline Distant metastasis & & & 0.443 & & 0.394 & & 0.331 & & 0.279 \\
\hline Positive & 8 & $6(75)$ & & $1(13)$ & & $6(75)$ & & $0 \quad(0)$ & \\
\hline Negative & 77 & $50(65)$ & & $19(25)$ & & $46(60)$ & & $12(16)$ & \\
\hline Nerve invasion & & & 0.015 & & 0.103 & & 0.205 & & 0.386 \\
\hline Positive & 29 & $24(83)$ & & $4(14)$ & & $24(83)$ & & $5(17)$ & \\
\hline Negative & 56 & $32(57)$ & & $16(29)$ & & $28(50)$ & & $7(13)$ & \\
\hline Vessel invasion & & & 0.056 & & 0.520 & & 0.323 & & 0.193 \\
\hline Positive & 19 & $16(84)$ & & $4(21)$ & & $13(68)$ & & $2(11)$ & \\
\hline Negative & 66 & $40(61)$ & & $16(24)$ & & $39(60)$ & & $10(15)$ & \\
\hline
\end{tabular}


Table IV. Correlation between the expression of mucins and clinicopathologic factors for intrahepatic cholangiocarcinoma.

\begin{tabular}{|c|c|c|c|c|c|c|c|c|c|}
\hline \multirow[b]{2}{*}{ Category } & \multirow[b]{2}{*}{ Total } & \multicolumn{2}{|c|}{ MUC1 } & \multicolumn{2}{|c|}{ MUC2 } & \multicolumn{2}{|c|}{ MUC5AC } & \multicolumn{2}{|c|}{ MUC6 } \\
\hline & & $+(\%)$ & P-value & $+(\%)$ & P-value & $+(\%)$ & P-value & $+(\%)$ & P-value \\
\hline Differentiation & & & 0.003 & & 0.293 & & 0.098 & & 0.215 \\
\hline Well & 14 & $3(21)$ & & $6(43)$ & & $8(57)$ & & $3(21)$ & \\
\hline Moderately & 13 & $11(85)$ & & $2(15)$ & & $7(54)$ & & $2(15)$ & \\
\hline Poorly & 7 & $5(71)$ & & $2(29)$ & & $1(14)$ & & $0 \quad(0)$ & \\
\hline $\mathrm{T}$ category & & & 0.072 & & 0.367 & & 0.56 & & 0.465 \\
\hline $\mathrm{T} 1$ & 24 & $11(46)$ & & $8(33)$ & & $11(46)$ & & $3(13)$ & \\
\hline$\geq \mathrm{T} 2$ & 10 & $8(80)$ & & $2(20)$ & & $5(50)$ & & $2(20)$ & \\
\hline $\mathrm{LN}$ metastasis & & & 0.452 & & 0.584 & & 0.389 & & 0.353 \\
\hline Positive & 6 & $4(67)$ & & $2(33$ & & $2(33)$ & & $0 \quad(0)$ & \\
\hline Negative & 28 & $15(54)$ & & $8(29)$ & & $14(50)$ & & $5(18)$ & \\
\hline Distant metastasis & & & 0.162 & & 0.338 & & 0.455 & & 0.611 \\
\hline Positive & 3 & $3(100)$ & & $0 \quad(0)$ & & $2(67)$ & & $0 \quad(0)$ & \\
\hline Negative & 31 & $16(52)$ & & $10(32)$ & & $14(45)$ & & $5(16)$ & \\
\hline Nerve invasion & & & 0.305 & & 0.492 & & 0.695 & & 0.724 \\
\hline Positive & 2 & $2(100)$ & & $0 \quad(0)$ & & $2(100)$ & & $0 \quad(0)$ & \\
\hline Negative & 32 & $17(54)$ & & $10(31)$ & & $14(44)$ & & $5(16)$ & \\
\hline Vessel invasion & & & 0.162 & & 0.338 & & 0.136 & & 0.611 \\
\hline Positive & 3 & $3(100)$ & & $\begin{array}{ll}0 & (0)\end{array}$ & & $\begin{array}{ll}0 & (0)\end{array}$ & & $0 \quad(0)$ & \\
\hline Negative & 31 & $16(52)$ & & $10(32)$ & & $16(52)$ & & $5(16)$ & \\
\hline Gross type & & & 0.005 & & 0.431 & & 0.126 & & 0.064 \\
\hline IG & 12 & $3(25)$ & & $5(38)$ & & $6(50)$ & & $3(25)$ & \\
\hline PI & 7 & $4(57)$ & & $1(14)$ & & $5(72)$ & & $2(28)$ & \\
\hline $\mathrm{MF}$ & 15 & $12(80)$ & & $4(23)$ & & $4(27)$ & $11(73.3)$ & $0 \quad(0)$ & \\
\hline
\end{tabular}

IG, intraductal growth; PI, periductal infiltrative; MF, mass forming.

Statistical analysis. SPSS 15.0 software (SPSS, Chicago, IL USA) used for statistical analysis. The clinicopathological characteristics were compared with expression of mucins using the $\chi^{2}$ test. Overall survival was considered as the period of survival between the time of surgery and the date of death by disease or at the last follow-up. Survival curves were calculated by the Kaplan-Meier method and the differences among the curves were analyzed by use of the log rank test. Cox's proportional hazard model was used for multivariate survival analysis. For all tests, a p-value $<0.05$ was considered to be statistically significant.

\section{Results}

Expression of mucins in cholangiocarcinoma, gallbladder and pancreatic adenocarcinoma. The expression pattern of each mucin is shown Fig. 1. MUC1 was expressed in the luminal border and cytoplasm of cancer cells. MUC2, MUC5AC and MUC6 were mainly expressed in the cyto- plasm of cancer cells. The expression of MUC1, MUC2, MUC5AC and MUC6 was identified in 56 (65.8\%), 20 $(23.5 \%), 52(61.1 \%)$ and $12(14.1 \%)$ of the $85 \mathrm{CCs}$, respectively. There was no significant difference for expression of mucins among CCs, pancreatic adenocarcinoma and gallbladder adnocarcinoma (Table I).

A higher degree of MUC5AC expression was observed in ECCs than in ICCs ( $\mathrm{p}=0.026)$ (Table II). There was no significant difference of MUC1, MUC2 and MUC6 expression between ICCs and ECCs. MUC1 expression showed a significant correlation with poor differentiation $(\mathrm{p}=0.002)$, higher $\mathrm{T}$ category $(\mathrm{p}=0.003)$ and the presence of nerve invasion $(\mathrm{p}=0.015)$. There was a significant correlation between MUC5AC expression and a higher T category $(\mathrm{p}=0.013)$. In contrast, MUC6 was more frequently expressed in welldifferentiated tumors $(\mathrm{p}=0.010)$. MUC expression showed no correlation with the presence of a lymph node metastasis, distant metastasis and vessel invasion (Table III). When CCs were classified as ICCs and ECCs, MUC1 expression 
Table V. Correlation between the expression of mucins and clinicopathological factors for extrahepatic cholangiocarcinoma.

\begin{tabular}{|c|c|c|c|c|c|c|c|c|c|}
\hline \multirow[b]{2}{*}{ Category } & \multirow[b]{2}{*}{ Total } & \multicolumn{2}{|c|}{ MUC1 } & \multicolumn{2}{|c|}{ MUC2 } & \multicolumn{2}{|c|}{ MUC5AC } & \multicolumn{2}{|c|}{ MUC6 } \\
\hline & & $+(\%)$ & P-value & $+(\%)$ & P-value & $+(\%)$ & P-value & $+(\%)$ & P-value \\
\hline Differentiation & & & 0.017 & & 0.204 & & 0.486 & & 0.007 \\
\hline Well & 23 & $13(57)$ & & $6(26)$ & & $15(65)$ & & $7(30)$ & \\
\hline Moderately & 24 & $20(83)$ & & $4(17)$ & & $18(75)$ & & $0 \quad(0)$ & \\
\hline Poorly & 4 & $4(100)$ & & $0 \quad(0)$ & & $3(75)$ & & $0 \quad(0)$ & \\
\hline $\mathrm{T}$ category & & & 0.079 & & 0.15 & & 0.034 & & 0.282 \\
\hline $\mathrm{T} 1$ & 16 & $9(56)$ & & $5(31)$ & & $8(50)$ & & $1(6)$ & \\
\hline$\geq \mathrm{T} 2$ & 35 & $28(80)$ & & $5(14)$ & & $28(77)$ & & $6(17)$ & \\
\hline LN metastasis & & & 0.428 & & 0.567 & & 0.233 & & 0.471 \\
\hline Positive & 12 & $8(67)$ & & $2(17)$ & & $10(83)$ & & $1(8)$ & \\
\hline Negative & 39 & $29(74)$ & & $8(21)$ & & $26(64)$ & & $6(15)$ & \\
\hline Distant metastasis & & & 0.421 & & 0.681 & & 0.537 & & 0.462 \\
\hline Positive & 5 & $3(60)$ & & $1(20)$ & & $4(80)$ & & $0 \quad(0)$ & \\
\hline Negative & 46 & $34(74)$ & & $9(20)$ & & $32(69)$ & & $7(15)$ & \\
\hline Nerve invasion & & & 0.115 & & 0.287 & & 0.066 & & 0.261 \\
\hline Positive & 27 & $22(82)$ & & $4(15)$ & & $22(82)$ & & $5(19)$ & \\
\hline Negative & 24 & $15(63)$ & & $6(25)$ & & $14(59)$ & & $2(8)$ & \\
\hline Vessel invasion & & & 0.278 & & 0.381 & & 0.215 & & 0.619 \\
\hline Positive & 16 & $13(81)$ & & $4(25)$ & & $13(81)$ & & $2(13)$ & \\
\hline Negative & 35 & $24(69)$ & & $6(17)$ & & $23(66)$ & & $5(14)$ & \\
\hline Gross type & & & 0.006 & & 0.269 & & 0.068 & & 0.429 \\
\hline IG & 17 & $8(47)$ & & $5(29)$ & & $8(47)$ & & $3(18)$ & \\
\hline PI & 34 & $29(85)$ & & $5(15)$ & & $7(21)$ & & $4(12)$ & \\
\hline
\end{tabular}

IG, intraductal growth; PI, periductal infiltrative.

correlated with tumor differentiation $(\mathrm{p}=0.003)$ and macroscopic classification ( $\mathrm{p}=0.005)$ for ICCs (Table IV). For ECCs, MUC1 expression showed a significant correlation with differentiation $(\mathrm{p}=0.017)$ and the periductal-infiltrative type $(\mathrm{p}=0.006)$. MUC5AC was more frequently expressed for a higher $\mathrm{T}$ category in ECCs $(\mathrm{p}=0.034)$. There was significant inverse correlation between MUC6 expression and tumor differentiation for ECCs $(\mathrm{p}=0.007)$ (Table V).

Survival analysis. The median survival time for patients with a CC was 20.6 months. Based on the use of univariate analysis, patients with MUC1-positive cancers had significantly poorer survival as compared to patients with MUC1negative cancers $(\mathrm{p}=0.015)$. Other factors that correlated with survival were tumor differentiation, $\mathrm{T}$ category, the presence of a lymph node metastasis and a distant metastasis (Table VI). The expression of MUC2, MUC5AC and MUC6 showed no correlation with overall survival (Fig. 2). The use of multivariate analysis determined that $\mathrm{T}$ category and the presence of a lymph node metastasis were independent prognostic factors (Table VII).

\section{Discussion}

This study demonstrated the following findings. i) MUC1 expression was correlated with tumor progression and patient survival for cholangiocarcinoma (CC). ii) MUC5AC was more frequently expressed in an advanced CC. iii) MUC6 expression was more observed in a well-differentiated $\mathrm{CC}$. iv) The expression patterns of mucins in $\mathrm{CC}$, pancreatic adenocarcinoma and gallbladder adenocarcinoma were not different. MUC1 is a membrane bound type mucin detected in most epithelial cells $(3,5)$. MUC1 is frequently expressed both in developing intrahepatic bile ducts in the fetal liver and in CCs, but is absent in the normal adult intrahepatic biliary tree $(14,15)$. In cancer cells, abnormal mucins are synthesized and can potentially be used as markers for the development and progression of tumors. In the present study, we found that MUC1 expression was significantly associated with tumor progression factors such as poor differentiation, an advanced tumor stage and nerve invasion. Moreover, increased expression of MUC1 in CC tissues was correlated with poor survival of $\mathrm{CC}$ patients. These results are in 
Table VI. Univariate analysis for overall survival for cholangiocarcinoma.

\begin{tabular}{|c|c|c|c|c|c|}
\hline \multirow[b]{2}{*}{ Category } & \multirow[b]{2}{*}{ No. } & \multicolumn{3}{|c|}{ Overall survival, mean, 95\% CI } & \multirow[b]{2}{*}{ P-value } \\
\hline & & Lower bound & Median & Upper bound & \\
\hline MUC1 expression & & & & & 0.015 \\
\hline Positive & 58 & 21.635 & 29.213 & 36.791 & \\
\hline Negative & 27 & 41.012 & 56.479 & 71.945 & \\
\hline Differentiation & & & & & 0.027 \\
\hline Well & 37 & 37.111 & 50.350 & 63.590 & \\
\hline Moderately & 37 & 22.079 & 33.005 & 43.932 & \\
\hline Poorly & 11 & 12.706 & 19.184 & 25.661 & \\
\hline $\mathrm{T}$ category & & & & & $<0.001$ \\
\hline $\mathrm{T} 1$ & 40 & 41.895 & 54.333 & 66.770 & \\
\hline$\geq \mathrm{T} 2$ & 45 & 15.551 & 20.061 & 24.571 & \\
\hline LN metastasis & & & & & $<0.001$ \\
\hline Positive & 18 & 9.120 & 12.861 & 16.603 & \\
\hline Negative & 67 & 35.140 & 45.172 & 55.205 & \\
\hline Distant metastasis & & & & & 0.012 \\
\hline Positive & 8 & 10.352 & 14.535 & 18.718 & \\
\hline Negative & 77 & 32.685 & 42.228 & 51.770 & \\
\hline Nerve invasion & & & & & 0.082 \\
\hline Positive & 29 & 21.332 & 32.784 & 44.236 & \\
\hline Negative & 56 & 30.189 & 41.043 & 51.896 & \\
\hline Vessel invasion & & & & & 0.412 \\
\hline Positive & 19 & 19.840 & 28.509 & 37.177 & \\
\hline Negative & 66 & 32.074 & 43.003 & 53.932 & \\
\hline
\end{tabular}

95\% CI, $95 \%$ confidence interval.

agreement with findings of previous reports $(16,17)$. Several experimental studies may explain the finding that MUC1 expression is correlated with tumor progression $(9-11,18,19)$. MUC1 expressed on cancer cells may inhibit interactions between cytotoxic lymphocytes and tumor cells (11) or may function as an anti-adhesion molecule that inhibits cell-cell adhesion $(9,10,18,19)$.

In the present study, we subdivided the ICCs into three gross types, the mass-forming, periductal-infiltrative and intraductal growth type, according to the recommendations of the Liver Cancer Study Group in Japan. Our study demonstrated that MUC1 expression was significantly higher in the mass-forming type as compared to the other types of ICCs. For ECCs, MUC1 expression was higher in the periductal infiltrative type as compared to the intraductal growth type. However, other types of mucin expression did not correlate with the gross types of ICCs in this study. Similarly, a previous study has reported that the mass-forming type showed significantly higher MUC1 expression as compared to the periductal infiltrative and intraductal growth type (16). In contrast to our results, Suh et al have reported that MUC1 expression was not significantly different based on gross type, and MUC2 was highly expressed only in the intraductal growth type and was never expressed in the mass-forming and periductal infiltrative types of ICCs (20).

MUC5AC is a gel-forming mucin that is expressed in gastric foveolar cells and is expressed in tracheobronchial epithelial cells. Aberrant expression of MUC5AC has been reported in preneoplastic lesions and in carcinomas arising from intrahepatic and extrahepatic bile ducts (21). A recent study has shown that the MUC5AC-expressing gastric foveolar type of ICC was more often associated with aggressive tumor development, whereas the pyloric gland type exhibited less aggressive behavior. Furthermore, the determination of serum MUC5AC expression may be predictive of poor patient outcome and the presence of serum MUC5AC has shown high sensitivity and specificity for the presence of a CC (22,23). Boonla et al (22) have suggested a possible mechanism for the relationship between MUC5AC expression and malignant progression. First, MUC5AC is negativelycharged and cells that express high levels may repel each other and enhance cell migration. Second, the highly viscous 

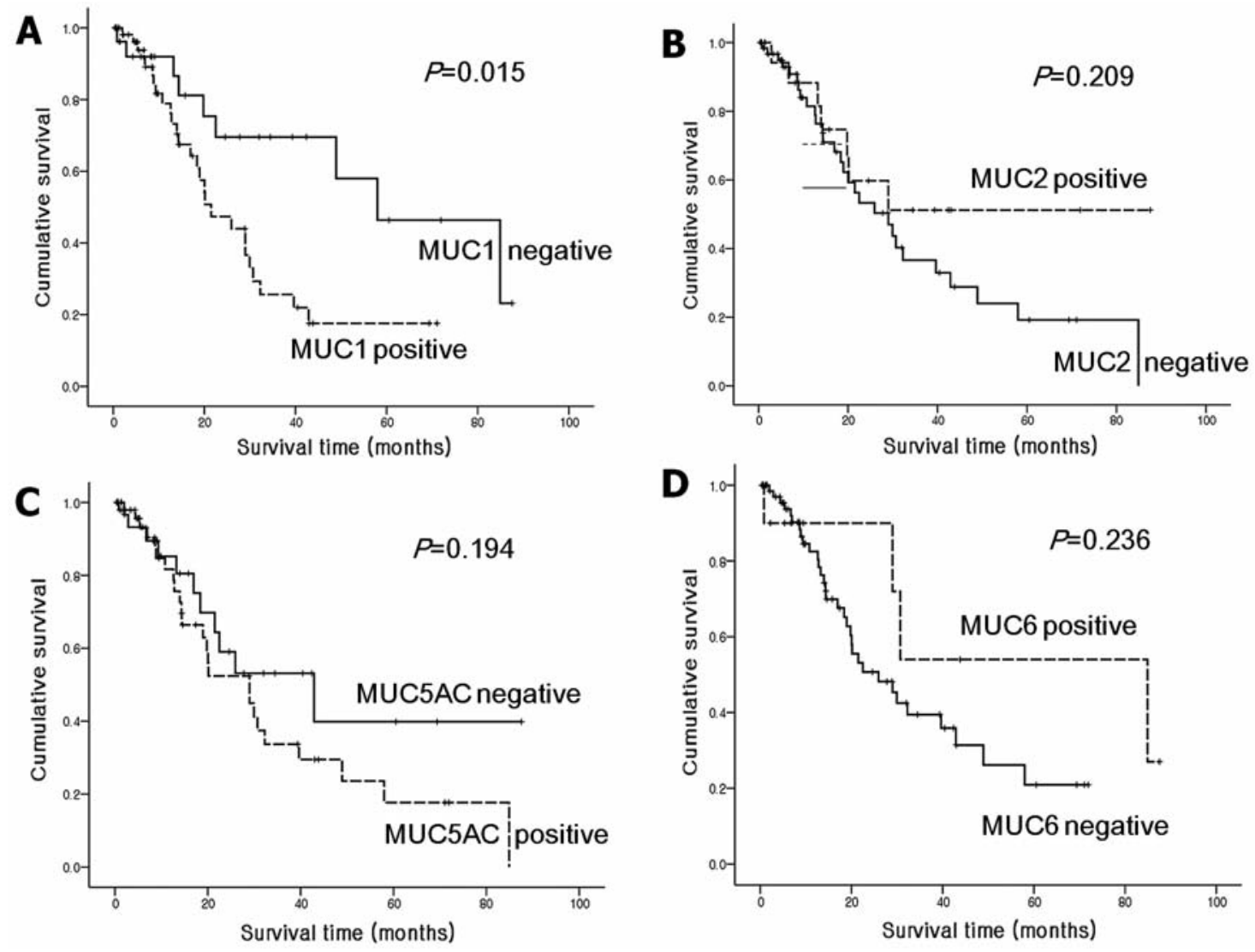

Figure 2. Survival curves of a cholangiocarcinoma patient according to mucin expression of mucins were determined by use of the Kaplan-Meier method. (A) MUC1, (B) MUC2, (C) MUC5AC and (D) MUC6.

Table VII. Multivariate Cox regression analysis for overall survival in cholangiocarcinoma.

\begin{tabular}{lccc}
\hline Factors & $\begin{array}{c}\text { Hazard } \\
\text { ratio }\end{array}$ & 95\% CI & P-value \\
\hline $\begin{array}{l}\text { MUC1 (positive } \\
\text { vs negative) }\end{array}$ & 1.211 & $0.403-3.640$ & 0.733 \\
$\begin{array}{l}\text { Differentiation } \\
\text { Well }\end{array}$ & Reference & - & 0.613 \\
$\begin{array}{l}\text { Moderately } \\
\text { Poorly }\end{array}$ & 1.420 & $0.564-3.572$ & 0.456 \\
T category (T1 & 1.743 & $0.560-5.421$ & 0.337 \\
vs $\geq$ T2) & 2.548 & $1.029-6.310$ & 0.043 \\
$\begin{array}{l}\text { LN metastasis } \\
\text { (presence vs absence) }\end{array}$ & 3.458 & $1.250-9.569$ & 0.017 \\
$\begin{array}{l}\text { Distant metastasis } \\
\text { (presence vs absence) }\end{array}$ & 0.784 & $0.222-2.770$ & 0.706 \\
\hline
\end{tabular}

LN, lymph node; $95 \%$ CI, 95\% confidence interval.

gel formed by MUC5AC surrounds the tumor emboli and may protect the tumor from proteolysis and limit the escape of immunogenic cells. In our study, MUC5AC expression was significantly associated with a higher T category. However, the association between high expression of MUC5AC and poor survival of patients with CC was not statistically significant. MUC5AC is frequently over-expressed in ICCs that arise in the large bile duct. According to the level of the involved bile duct, ICCs can be separated as hilar and peripheral types. MUC5AC is frequently expressed in ICCs from the hilar portion of the liver $(21,24)$. We found that the frequency of MUC5AC expression in ECCs (70.6\%) was significantly higher as compared to expression in ICCs (47.1\%). Similarly, Lee et al have shown that MUC5AC is more frequently expressed in ECCs $(44.0 \%)$ than in ICCs $(60.0 \%)$ (25). However, only a limited number of studies have compared the expression of MUC5AC in ICCs and ECCs. A further study with a large number of cases may clarify this point.

MUC6 is expressed in a wide variety of epithelial tissues including the gastric pyloric gland, duodenal Brunner's gland, gallbladder and seminal vesicle (26). MUC6 expression has been reported in malignant epithelial tissues of the lung, breast, prostate, pancreas and stomach (25-30). Previous studies have reported that MUC6 expression is related with tumor progression and metastatic potential in various cancers (25-31). A few reports on the clinical impact of the expression of MUC6 in CC patients are available $(24,32)$. MUC6 was expressed predominantly in well-differentiated ICC tumors and MUC6 expression in a pyloric gland type CC exhibited less aggressive behavior (24). Thuwajit et al have demonstrated that the expression of MUC6 showed a good correlation with the survival of CC patients (32). Our study also 
showed that MUC6 expression was correlated with tumor histological grade (well differentiation). A high production of MUC6 may act as a barrier to cancerous extension, resulting in less aggressive biological behavior in mucinous carcinoma of the breast (29). MUC6 expression in ICCs may be related to histological differentiation and lower levels of invasiveness; however, further investigations are needed to clarify the mechanisms of MUC6 expression that are associated with favorable outcome in patients with $\mathrm{CC}$.

Depending on the primary site of origin, $\mathrm{CC}$, especially ECC, may extend to the gallbladder and pancreas. Since all of these organs may give rise to carcinomas with similar morphological features, identification of the exact origin relies on precise macroscopy but may be impossible in a larger tumor (33). Many studies have made efforts to distinguish CC from pancreas and gallbladder adenocarcinoma. Duval et al have tried to identify the site of origin using cytokeratin expression and they have suggested that it is not possible to differentiate these tumors based solely on cytokeratin expression (34). Lee et al have reported that pancreas cancers and ECCs were characterized as MUC5AC positive, whereas gallbladder and ampulla of Vater cancers were negative for MUC5AC expression (25). This finding is different from our findings, which revealed that most of the tumors in these sites were highly positive for expression of MUC1 and MUC5AC. Moreover, there was no significant difference for the expression patterns of mucins for CC, gallbladder and pancreas cancer. Our results suggest that the expression profile of mucins cannot identify the site of origin for tumors of the pancreas, gallbladder and bile ducts.

In conclusion, high expression of MUC1 significantly correlates with an infiltrative growth pattern, dedifferentiation, nerve invasion and patient poor survival. These results suggest that MUC1 may play a role in CC progression and MUC1 can be considered as a useful prognostic indicator.

\section{Acknowledgements}

This study was supported by a grant of the Korean Ministry of Education, Science and Technology (The Regional Core Research Program/The Center for Healthcare Technology Development).

\section{References}

1. Khan SA, Davidson BR, Goldin R, Pereira SP, Rosenberg WM, Taylor-Robinson SD, Thillainayagam AV, Thomas HC, Thursz MR and Wasan H: Guidelines for the diagnosis and treatment of cholangiocarcinoma: consensus document. Gut 51: $1-9,2002$.

2. Shaib Y and El-Serag HB: The epidemiology of cholangiocarcinoma. Semin Liver Dis 24: 115-125, 2004.

3. Dekker J, Rossen JW, Buller HA and Einerhand AW: The MUC family: an obituary. Trends Biochem Sci 27: 126-131, 2002.

4. Higuchi T, Orita T, Nakanishi S, Katsuya K, Watanabe H, Yamasaki Y, Waga I, Nanayama T, Yamamoto Y, Munger W, Sun HW, Falk RJ, Jennette JC, Alcorta DA, Li H, Yamamoto T, Saito Y and Nakamura M: Molecular cloning, genomic structure, and expression analysis of MUC20, a novel mucin protein, upregulated in injured kidney. J Biol Chem 279: 1968-1979, 2004.

5. Taylor-Papadimitriou J, Burchell JM, Plunkett T, Graham R, Correa I, Miles D and Smith M: MUC1 and the immunobiology of cancer. J Mammary Gland Biol Neoplasia 7: 209-221, 2002.
6. Gum JR Jr, Hicks JW, Gillespie AM, Carlson EJ, Komuves L, Karnik S, Hong JC, Epstein CJ and Kim YS: Goblet cellspecific expression mediated by the MUC2 mucin gene promoter in the intestine of transgenic mice. Am J Physiol 276: 666-676, 1999.

7. Horinouchi M, Nagata K, Nakamura A, Goto M, Takao S, Sakamoto M, Fukushima N, Miwa A, Irimura T and Imai K: Expression of different glycoforms of membrane mucin (MUC1) and secretory mucin (MUC2, MUC5AC and MUC6) in pancreatic neoplasms. Acta Histochem Cytochem 36: 443-453, 2003.

8. Kim YS and Gum JR Jr: Diversity of mucin genes, structure, function, and expression. Gastroenterology 109: 999-1001, 1995.

9. Kondo K, Kohno N, Yokoyama A and Hiwada K: Decreased MUC1 expression induces E-cadherin-mediated cell adhesion of breast cancer cell lines. Cancer Res 58: 2014-2019, 1998.

10. Makiguchi Y, Hinoda Y and Imai K: Effect of MUC1 mucin, an anti-adhesion molecule, on tumor cell growth. Jpn J Cancer Res 87: 505-511, 1996.

11. Van de Wiel-van Kemenade E, Ligtenberg MJ, De Boer AJ, Buijs F, Vos HL, Melief CJ, Hilkens J and Figdor CG: Episialin (MUC1) inhibits cytotoxic lymphocyte-target cell interaction. J Immunol 151: 767-776, 1993.

12. Hamilton SR and Aaltonen LA: Pathology and genetics of tumours of the digestive system. IARC press, Lyon, pp173-180, 2004.

13. Greene FL, Page DL, Fleming ID, Fritz A, Balch CM, Haller DG and Morrow M: American Joint Committee on Cancer: Cancer Staging Manual. 6th edition. Springer-Verlag, pp131-138, 2002.

14. Yamashita K, Yonezawa S, Tanaka S, Shirahama H, Sakoda K, Imai K, Xing PX, McKenzie IF, Hilkens J and Kim YS: Immunohistochemical study of mucin carbohydrates and core proteins in hepatolithiasis and cholangiocarcinoma. Int J Cancer 55: 82-91, 1993.

15. Sasaki M and Nakanuma Y: Expression of mucin core protein of mammary type in primary liver cancer. Hepatology 20: 1192-1197, 1994.

16. Higashi M, Yonezawa S, Ho JJ, Tanaka S, Irimura T, Kim YS and Sato E: Expression of MUC1 and MUC2 mucin antigens in intrahepatic bile duct tumors: its relationship with a new morphological classification of cholangiocarcinoma. Hepatology 30: $1347-1355,1999$

17. Tamada S, Goto M, Nomoto M, Nagata K, Shimizu T, Tanaka S, Sakoda K, Imai K and Yonezawa S: Expression of MUC1 and MUC2 mucins in extrahepatic bile duct carcinomas: its relationship with tumor progression and prognosis. Patho Int 52: 713-723, 2002.

18. Wesseling J, van der Valk SW, Vos HL, Sonnenberg A and Hilkens J: Episialin (MUC1) overexpression inhibits integrinmediated cell adhesion to extracellular matrix components. J Cell Biol 129: 255-265, 1995.

19. Wesseling J, van der Valk SW and Hilkens J: A mechanism for inhibition of E-cadherin-mediated cell-cell adhesion by the membrane-associated mucin episialin/MUC1. Mol Biol Cell 7: 565-577, 1996.

20. Suh KS, Chang SH, Lee HJ, Roh HR, Kim SH and Lee KU: Clinical outcomes and apomucin expression of intrahepatic cholangiocarcinoma according to gross morphology. J Am Coll Surg 195: 782-789, 2002.

21. Sasaki M, Nakanuma Y and Kim YS: Characterization of apomucin expression in intrahepatic cholangiocarcinomas and their precursor lesions: an immunohistochemical study. Hepatology 24: 1074-1078, 1996.

22. Boonla C, Wongkham S, Sheehan JK, Wongkham C, Bhudhisawasdi V, Tepsiri N and Pairojkul C: Prognostic value of serum MUC5AC mucin in patients with cholangiocarcinoma. Cancer 98: 1438-1443, 2003.

23. Wongkham S, Sheehan JK, Boonla C, Patrakitkomjorn S, Howard M, Kirkham S, Sripa B, Wongkham C and Bhudhisawasdi V: Serum MUC5AC mucin as a potential marker for cholangiocarcinoma. Cancer Lett 195: 93-99, 2003.

24. Aishima S, Kuroda Y, Nishihara Y, Taguchi K, Taketomi A, Maehara Y and Tsuneyoshi M: Gastric mucin phenotype defines tumour progression and prognosis of intrahepatic cholangiocarcinoma: gastric foveolar type is associated with aggressive tumour behavior. Histopathology 49: 35-44, 2006.

25. Lee MJ, Lee HS, Kim WH, Choi Y and Yang M: Expression of mucins and cytokeratins in primary carcinomas of the digestive system. Mod Pathol 16: 403-410, 2003. 
26. Bartman AE, Buisine MP, Aubert JP, Niehans GA, Toribara NW, Kim YS, Kelly EJ, Crabtree JE and Ho SB: The MUC6 secretory mucin gene is expressed in a wide variety of epithelial tissues. J Pathol 186: 398-405, 1998

27. Awaya H, Takeshima Y, Yamasaki M and Inai K: Expression of MUC1, MUC2, MUC5AC and MUC6 in atypical adenomatous hyperplasia, bronchioloalveolar carcinoma, adenocarcinoma with mixed subtypes, and mucinous bronchioloalveolar carcinoma of the lung. Am J Clin Pathol 121: 644-653, 2004.

28. Cozzi PJ, Wang J, Delprado W, Perkins AC, Allen BJ, Russell PJ and Li Y: MUC1, MUC2, MUC4, MUC5AC and MUC6 expression in the progression of prostate cancer. Clin Exp Metastasis 22: 565-573,2005

29. Matsukita S, Nomoto M, Kitajima S, Tanaka S, Goto M Irimura T, Kim YS, Sato E and Yonezawa S: Expression of mucins (MUC1, MUC2, MUC5AC and MUC6) in mucinous carcinoma of the breast: comparison with invasive ductal carcinoma. Histopathology 42: 26-36, 2003.
30. Lee HS, Lee HK, Kim HS, Yang HK and Kim WH: Tumour suppressor gene expression correlates with gastric cancer prognosis. J Pathol 200: 39-46, 2003.

31. Chang HJ, Kim SW, Lee BL, Hong EK and Kim WH: Phenotypic alterations of mucins and cytokeratins during gallbladder carcinogenesis. Pathol Int 54: 576-584, 2004.

32. Thuwajit P, Chawengrattanachot $\mathrm{W}$, Thuwajit C, Sripa B, Paupairoj A and Chau-In S: Enhanced expression of mucin 6 glycoprotein in cholangiocarcinoma tissue from patients in Thailand as a prognostic marker for survival. J Gastroenterol Hepatol 23: 771-778, 2008.

33. Esposito I and Schirmacher P: Pathological aspects of cholangiocarcinoma. HPB 10: 83-86, 2008.

34. Duval JV, Savas L and Banner BF: Expression of cytokeratins 7 and 20 in carcinomas of the extrahepatic biliary tract, pancreas, and gallbladder. Arch Pathol Lab Med 124: 1196-1200, 2000. 